\title{
IMPLEMENTATION OF INTEGRATED MANAGEMENT SYSTEM IN ORDER TO ENHANCE EQUIPMENT EFFICIENCY
}

\author{
Viliam ZALOGA, Konstiantyn DYADYURA, Iryna RYBALKA \\ Sumy State University \\ Iveta PANDOVA \\ Technical University of Kosice
}

\begin{abstract}
:
The main aim of presented article is to present methodology how sophisticated products as compressor equipment can be considered and analysed as a complex technical system which consists of jointly operating components - a set of hardware, software, operational staff and documented information. In process modelling, these components are interacting in different processes of inputs, outputs, mechanisms (resources) or management. Based on the regulatory requirements for each component of the system, a key efficiency indicator can be identified. This allows to control the process and make appropriate decisions to improve the system. The application of the proposed methodology for the development and implementation of an integrated management system reduce the cost of resources and significantly improve the quality of the implementation of processes.
\end{abstract}

Key words: complex technical system, integrated management system, standards

\section{INTRODUCTION}

Countries' productive structures are determined by the local availability of specific inputs with more capabilities required for sophisticated products (SP) (for example, technological equipment). Together with technological opportunities, companies should take into account issues of ecology, labour safety, social responsibility, personnel management, etc. in their work. It is possible to solve the problems by introducing modern integrated management systems based on the practice and experience of successful international companies [17, 19].

When jointly implementing standards for management systems developed by ISO (such as ISO 9001:2015, ISO 14001:2015, ISO 45001:2018 [6, 7, 8] and others), the process of creating an integrated management system is greatly facilitated by the fact that all these standards are developed using common approaches, in the general, if you can say so, economic situation and using a single policy of technical regulation. All this allows you to combine the requirements of different control systems in a single, integrated management system $[3,15,21]$.

However, existing scientific developments and methodological materials do not address the simultaneous implementation of requirements standards developed in different countries, and, therefore, in different economic and social conditions, and that have specific national differences.
An even more difficult situation is when a single system of standards is already implemented in the organization and is functioning successfully and the moment when the consumer demands from his supplier the introduction of a quality management system according to the industry standard (for example, ISO/TS 22163:2017 [9]).

Thus, there is a contradiction between the need for the development of integrated models that allow for the analysis of dynamic evolutionary processes occurring at the interval of the product lifecycle management (PLM) $[1,16$, 18] of sophisticated products, and the insufficiency of the existing regulatory and methodological support for the synthesis of such models in order to manage these processes. The solution to this problem is proposed to be sought in the creation and use of logical system-wide evolutionary models that must take into account the dynamic, parametric, economic, energy and operational processes occurring in each particular complex technical system $[5,10,12]$.

The methodology of informational support of a complex interconnected processes of the lifecycle (LC) system is suggested in the work, which allows to manage the organizational structure of multifunctional and multi-element technical and software components, as well as operational personnel to ensure consistency of the work sequence results at the stages of designing, manufacturing and daily operation. 


\section{LITERATURE REVIEW}

Comprehensive development of manufacturing management relies on complex, multifactorial approach study of various aspects determining operation and usability of technology systems. Quality and efficiency of particular system and/or process depends on level of implemented improvements achieved by research that is necessarily associated with strong erudition and deep understanding of technology.

Dong Wang et al [3] developed method of quality supervision for management evaluation purposes, in addition to standard methods $[6,7,8,9]$. In order to evaluate process parameters, Balara et al [1] developed signal processing procedure. Hang Wang \& Jun Zheng [5] and Su \& Jing Li [19] analysed technical details of virtual interface management, Militaru et al [12] reported methodology of software environment audits, Rimar et al [18] developed methodology of interaction analysis of the technical systems and environmental conditions.

Todic et al. [20], Durdan et al [4] and Krenicky [11] implemented multifactorial monitoring methods for evaluation of complex variation of characteristics. Cacko \& Krenicky [2], Panda et al [15, 16], Olejarova et al. [14] and Prislupcak et al. [17] provided analysis of exposed parts technical characteristics in order to determine the operating status and durability, Jurko et al. [10], Monkova \& Monka [13] and Valicek et al. [21] developed methods and gave examples of the evaluation of particular properties.

\section{METHODOLOGY OF RESEARCH}

On the basis of the analysis of the stages of PLM we consider and apply following levels:

- the product as an object of service;

- the product as an object of manufacture;

- the product as an object of improvement.

The level of operation of the product is primary, the level of manufacturing - the secondary, and the level of improvement - tertiary. The levels are interconnected with the help of direct and feedback links that provide continuous streams of information about the conditions of exploitation of the product (technological system), as well as the provision of product properties at the level of perfection and manufacturing. This approach allows us to take into account all functional features of product operation in the process of its manufacture and improvement. SP are regarded as independently functioning multipurpose complex and complex technical system (CTS). As a part of a CTS, in general, three different components can be distinguished a complex of technical means (CTM), software (SW) and operational personnel (OP). The composition of the FSj (as well as the composition of the system as a whole) generally consists of three components:

- group of $j$-th functions of technical means (TM) participating in the implementation ( $j$-th functional subsystem TM - FSS $T_{T M j}$ );

- group of software tools (ST) participating in the $j$-th function realization ( $j$-th functional subsystem ST FSS $\left.S_{T j}\right)$;
- group of ergatic means (EM) participating in the $j$-th function realization ( $j$-th functional subsystem EM FSS EMj $_{\text {). }}$

The components of the CTS (for example, compressor equipment [9]) are shown in Fig. 1. In the analysis of functional subsystems, multidimensionality of their indicators is observed. Key performance indicators and performance indicators, being derived, when using such a scheme characterize the overall process.

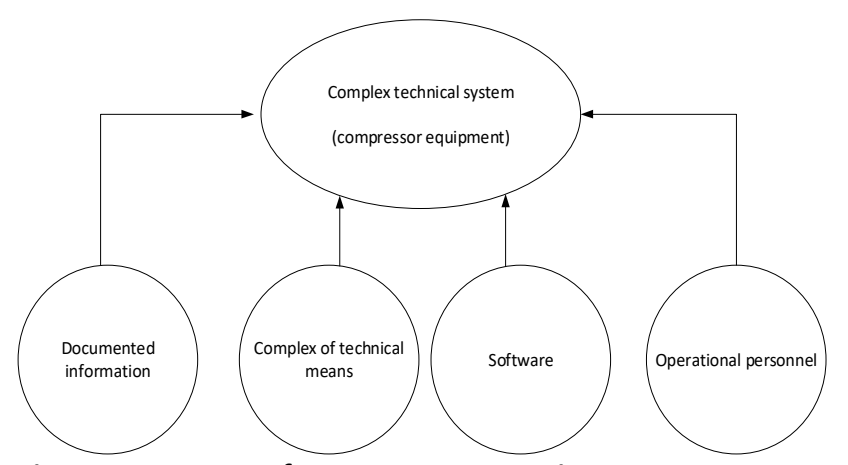

Fig. 1 Components of CTS compressor equipment

When considering information support for making decisions that ensuring compliance of sophisticated products with the established requirements for formation and optimization of production potential of the enterprise, which includes the main production funds, industrial production personnel, technology, energy and information resources, the classical scheme of construction of the function of production is made up of two stages. First, on the basis of qualitative analysis of modelling objects and its goals from the list of classes of mathematical functions $F=\left\{f\left(x_{1}, \ldots, x_{n}, a_{1}, \ldots, a_{k}\right)\right\}, \quad$ a parametric class $x_{1}, \ldots, x_{n}$ is selected, all elements of which as functions of having the corresponding characteristics.

Thus, a "type of production function (PF)" is established $[3,13,20]$. Then the function of this "type" $Y=$ $f\left(x_{1}, \ldots, x_{n} ; a_{1}, \ldots, a_{k}\right)$ is considered as a regression equation $\left(a_{1}, \ldots, a_{k}\right)$, the evaluation of which parameters are determined from the condition of minimizing the sum of squares of the deviations of the values of the function $f(x ; a)$ in the points of observation $x(t) t=1, \ldots, T$, from the values $Y(T), t=1, \ldots, T t=1, \ldots, T$ :

$$
\sum_{t=1}^{T}(y(t)-f(x(t) ; a))^{2} \rightarrow \min .
$$

The FSS functional subsystems cover a plurality of types of elements (FSS ${ }_{T M j}, F S S_{E M j}, F S S_{E M j}$ ), which allow the implementation of these functions and the level of effectiveness of which is determined by the range of their parameters. The possibility of forming various variants of the characteristics of the $C_{F S i}$ of the functional subsystem of processes is provided by a directed selection from the set $\left\{F S^{0}\right\}$ of a set of elements $F S S_{i} \subset F S^{0}$, which ensures the fulfilment of a set of functions $\left\{F^{0}\right\}$.

At the same time, it is necessary to take into account the uncertainty of the processes of the LC, which is associated with incomplete notions about the available opportunities or the timing of the product. As a result, the planned and real implementation of processes differ from each 
other. Changing the actual values of the components of the production function in time is shown in Fig. 2. At some point in time $T_{1}$ as a result of random action there is a deviation $\Delta Y\left(T_{1}\right)$ of their values from the planned ones. The process control system at the stages of the LC should find it and make it so that the actual $X_{f}$ and the planned value of the Xp parameter at time $\mathrm{T}_{2}$ are equal: $\Delta Y_{i}(T)=0$. In the functional subsystem, the change in the planned values of the parameters of the elements is related to the formation of the quality (Ch FSi $_{\text {) }}$ (Fig. 3) and cost (Fig. 4) of the SP project. In this case, to assess changes in parameter values components production functions can be used ranking function $F_{K}$.

$$
F_{K}=\eta \cdot \bar{X}+(1-\eta) \cdot \bar{V}, \bar{X}=\frac{\bar{X}_{i}-\bar{X}_{0}}{\overline{X X}_{0_{\max }}}, \bar{V}=\frac{\mathrm{T}_{f}-T_{0}}{\mathrm{~T}_{\mathrm{m}}-T_{0}}
$$

where:

$\bar{X}$ - the relative value of the change in the characteristics of the work;

$\bar{V}$ - the relative rate of change of characteristics $\bar{X}$;

$\bar{X}_{0}$ - value of the characteristic $\bar{X}$ at time $T_{0}$;

$\bar{X}_{i}-$ value of the characteristic $\bar{X}$ at time $T_{i}$;

$\bar{X}_{\text {max }}$ - the maximum allowable value $\bar{X}$;

$T_{n}$ - required (planned) duration of work execution;

$T_{f}$ - actual (projected) duration of work execution;

$\eta$ - the weighting factor characterizing the degree of influence of the arguments of the $F_{k}$ function on the estimation of the state of the LC of the product $(\eta=0-1)$.

One of the most convenient and fairly simple ways of using the calculation models (estimating across the whole set of parameters of the PFy) is based on the application of the Harrington generalized function of desirability [3, 4, 14].

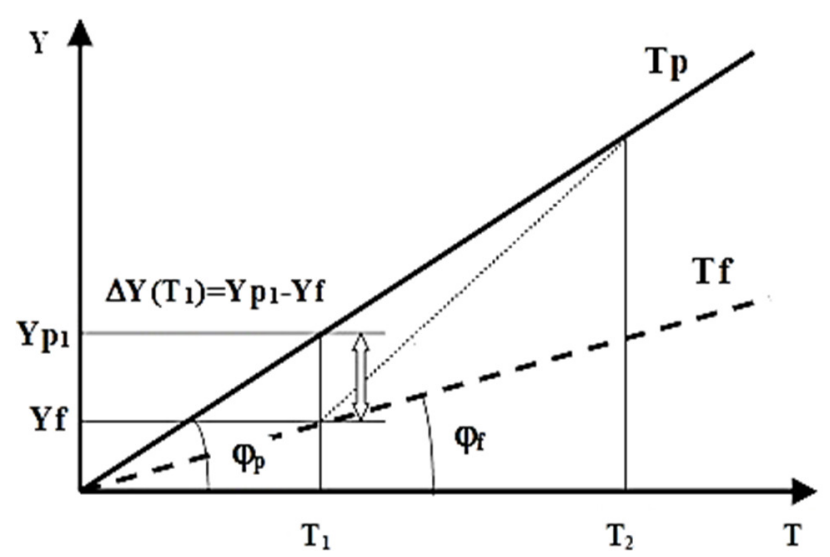

Fig. 2 Changing the scheduled values of components of production functions in time:

$Y_{P}(T)$ - planned value of the indicator; $Y_{F}(T)$ is the actual value of the indicator

The scale of desirability has an interval $d_{j}$ from 0 to 1 , where $d_{j}=1$ corresponds to the ideal calculation model with parameters $y_{i} d_{j}=0$ - totally inappropriate calculation data. Estimation of the calculated models on the scale of desirability is given in Table 1. The desirability function for the lower, upper, and middle grades has the following form (for one-way limit):

$$
\begin{gathered}
d \exp \left(-\exp \left(-y^{\prime}\right)\right)_{\min } ; d \exp \left(-\exp \left(y^{\prime}\right)\right)_{\text {max }}, \\
d_{m}=\frac{\left(\exp \left(-\exp \left(-y^{\prime}\right)\right)+1-\exp \left(-\exp \left(y^{\prime}\right)\right)\right)}{2},
\end{gathered}
$$

where:

$y^{\prime}$ is the coded value of the corresponding parameter $y$, that is, its value in the conditional scale: $y^{\prime}=b_{0}+b_{1} \cdot y$. The coefficients $b_{0}$ and $b_{1}$ are calculated at the appropriate points on the scale of desirability $(0.20,0.37,0.63$, 0.80) taking into account the formula:

$$
y^{\prime}=-\ln (-\ln d)
$$

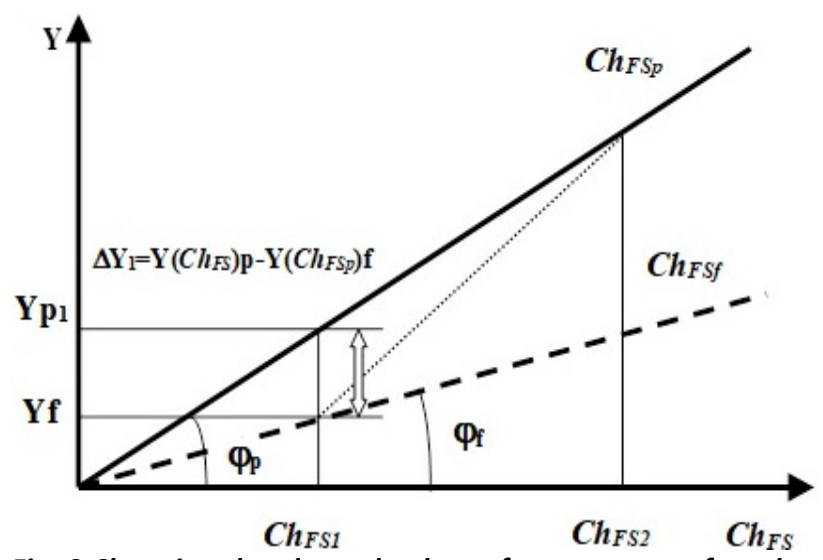

Fig. 3 Changing the planned values of components of production functions while ensuring the required quality of a product of a project

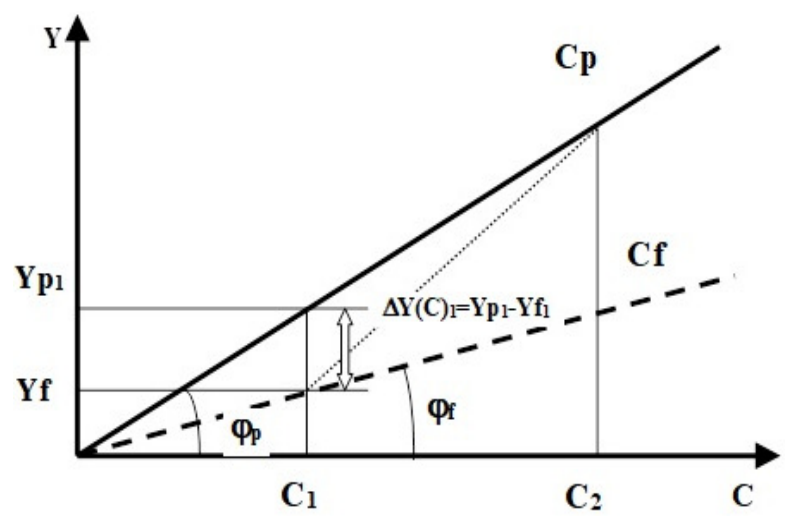

Fig. 4 Changing the planned values of components of production functions while ensuring the required cost of a project

\begin{tabular}{|c|c|c|c|c|c|}
\hline $\begin{array}{l}\text { Subjective } \\
\text { evaluation } \\
\text { of PF parameters }\end{array}$ & $\begin{array}{l}\text { High } \\
\text { level }\end{array}$ & $\begin{array}{l}\text { Good } \\
\text { level }\end{array}$ & $\begin{array}{c}\text { Sufficient } \\
\text { level }\end{array}$ & $\begin{array}{l}\text { Low } \\
\text { level }\end{array}$ & $\begin{array}{c}\text { Unwanted } \\
\text { level }\end{array}$ \\
\hline $\begin{array}{l}\text { Value of the } \\
\text { parameter } y_{j} \\
\text { on a scale } \\
\text { of desirability } d_{j}\end{array}$ & $\begin{array}{l}1.0- \\
0.8\end{array}$ & $\begin{array}{l}0.80- \\
0.63\end{array}$ & $0.63-0.37$ & $\begin{array}{l}0.37- \\
0.20\end{array}$ & $0.20-0$ \\
\hline $\begin{array}{l}\text { Numerical value } \\
\text { of the code }\end{array}$ & 2.25 & 1.49 & 0.67 & 0.0057 & -0.048 \\
\hline
\end{tabular}
product

Table 1

Level desirability

Thus, the Harrington function allows to identify models of production functions based on data describing a real production process.

Taking into account the restrictions on the volume of products produced and the production resources used in calculating the desirability function, the scope of the def- 
inition of the production function contains the points satisfying the conditions: $Y_{\min } \leq Y \leq Y_{\max }, X_{1 \text { min }} \leq X_{1} \leq X_{2 \max }$, $X_{2 \min } \leq X_{2} \leq X_{2 \min }, X_{3 \min } \leq X_{3} \leq X_{3 \min }$.

In the framework of this paper we consider the form of a production function, known as the Cobb-Douglas function $[2,11]$. To obtain the values of the function of desirability from the indices of the production function, an analytic relationship between $y_{i}$ and $y^{\prime}$ is used, which, taking into account the expression (5), has the form:

$$
y^{\prime}=b_{0}+b_{1} \cdot\left(\beta_{0}+\beta_{1} \cdot z_{1}+\beta_{2} \cdot z_{2}+\beta_{3} \cdot z_{3}\right)
$$$$
\text { or }
$$

$y^{\prime}=b_{0}+b_{1} \cdot \beta_{0}+b_{1} \cdot \beta_{1} \cdot z_{1}+b_{1} \cdot \beta_{2} \cdot z_{2}+b_{1} \cdot \beta_{3} \cdot z_{3}$.

Taking into account the values $y^{\prime}=-[\ln (-\ln d)]$ in Table 1 , the system of equations (6) has the form:

$$
\begin{gathered}
y_{\text {min }}^{\prime}=b_{0}+b_{1} \cdot \beta_{0}+b_{1} z_{1 \text { min }}+b_{1} \cdot \beta_{2} \cdot z_{2 \min }+b_{1} \cdot \beta_{3} \\
\cdot z_{3 \min } \\
y_{\max }^{\prime}=b_{0}+b_{1} \cdot \beta_{0}+b_{1} z_{1 \text { max }}+b_{1} \cdot \beta_{2} \cdot z_{2 \max }+b_{1} \cdot \beta_{3} \\
\cdot z_{3 \max .}
\end{gathered}
$$

The desirability function for the lower, upper, and middle grades has the following form:

$$
\begin{gathered}
d \exp \left(-\exp \left(-\left(b_{0}+b_{1} \cdot \beta_{0}+b_{1} \cdot \beta_{1} \cdot z_{1}+b_{1} \cdot \beta_{2} \cdot z_{2}+\right.\right.\right. \\
\left.\left.\left.b_{1} \cdot \beta_{3}\right)\right)\right)_{\text {min' }} \\
d \exp \left(-\exp \left(b_{0}+b_{1} \cdot \beta_{0}+b_{1} \cdot \beta_{1} \cdot z_{1}+b_{1} \cdot \beta_{2} \cdot z_{2}+b_{1}\right.\right. \\
\left.\left.\cdot \beta_{3}\right)\right)_{\text {max }} .
\end{gathered}
$$

Presented research is based on the information contained in the regulations and plans that regulate the activities of the entity; statistical and accounting reporting with the use of statistical processing methods. As indicators that characterize the state of the production system and determine the production function, are considered: the cost of fixed assets, working capital and the number of employees or industrial and production personnel.

We have defined the desired area of production function on the example of the machine-building enterprise.

The use of the approaches described above was applied on an example of a prototype with the following relationship between the planned and actually realized values of material and time resources:

1) planned cost of design and development $\mathrm{Cp}=5$ thousands standard accounting units (s.a.u.);

2) the cost of developing a prototype $\mathrm{Cpr}=10$ thousands s.a.u.;

3) planned duration of development $\mathrm{Tp}=100$ hours;

4) prototype development time $\mathrm{Tpr}=200$ hours.

\section{RESULTS}

Following results were calculated using methodology described above.

The ratio of the lower limit of the projected duration of the current development to the duration of the design and development of the prototype $T_{\min }=1.3$.

The ratio of the upper limit of the projected duration of the current development to the duration of the development of the prototype $\mathrm{T}_{\max }=2.5$.
The ratio of the lower limit of the projected value of the current development to the cost of developing the prototype $\mathrm{C}_{\min }=1.3$.

Theratio of the upper limit of the projected value of the current development to the cost of developing the prototype $\mathrm{C}_{\text {max }}=2.5$.

The calculation showed that if the duration of development of the current project exceeds one third of the prototype development $(T=1,3)$, the cost will exceed the cost of developing the prototype six times $(C=6.034)$. At the same time, for (9) the value of the desirability function $d=0,87$ is obtained, which defines the project as high level (Table 1). The calculation showed that when the development period is exceeded by a third $(T=1.3)$, the cost increases by $57 \%$ ( $C=1.57$ ), and the desirability function $d=0.786$ defines the project as a good level (Table 1).

The calculation showed that if the cost of the current development is exceeded by a third of the cost of developing the prototype $(T=1.3)$, the development time will increase by $4 \%$, and the desirability function will be $d=0.73$, which makes it possible to evaluate it as a good level (Table 1).

The calculation showed that if the cost of developing a prototype by one third $(C=1.3)$, the development time will increase by $16 \%(T=1.16)$, and the desirability function $(d=$ $0.746)$ determines how good the level is.

The calculation of the encoded value for the desired area of the definition of the production function is presented in Table 2. We construct the dependence of the desired level of production function on the use of main production assets, on the use of working capital and on the number of industrial and production personnel.

The algorithm for developing the process indicators is as follows:

1. Identify the process and its result.

2. Identify inputs-resources (resources processed in one process cycle) and inputs-mechanisms (resources ensuring multiple execution of the process-equipment, personnel).

3. Identify the inputs and controls (rules and requirements for the process)

4. Knowing the result that must be obtained, it is necessary to evaluate it quantitatively - to generate the outcome indicators. They can be either simple or calculated (by formula or otherwise).

5. Based on the inputs of the process, you can generate cost indicators.

6. Based on the mechanisms of the process, you can generate additional cost indicators.

7. The correctness of the process, in addition to the cost of performing activities, also reflects the performance indicators.

8. Performance indicators are calculated as the ratio of the result obtained to the time.

9. Calculation of key performance indicators is carried out on the basis of pre-selected KPI performance and KPI costs. Performance indicators, thus, are integral characteristics of activity. 
Table 2

The calculation of the encoded value for the desired area of the definition $f$ the production function

\begin{tabular}{|c|c|c|c|}
\hline$y_{\min }$ & $y_{\max }$ & $b_{1}=\frac{y}{\min _{\prime_{\text {max }}^{\prime}}^{y \max }}$ & $b_{0}=y_{\min }^{1_{\min }}$ \\
\hline 38.2 & 92.2 & $\begin{array}{c}0.0416 \\
y^{\prime}=0,041 \cdot y-1,58208\end{array}$ & -1.5821 \\
\hline$X_{1 \text { max }}$ & $X_{1 \max }$ & $b_{1}=\frac{y}{\min _{\prime_{\max }^{X}}^{X 1 \max _{1 \min }}}$ & $b_{0}=y_{\min }^{1_{11 \min }}$ \\
\hline 15.3 & 42 & $\begin{array}{c}0.084 \\
y_{1}^{\prime}=0,084 \cdot X_{1}-1,280468\end{array}$ & -1.28 \\
\hline$X_{2 \min }$ & $X_{2 \max }$ & $b_{1}=\frac{}{\min _{\prime_{\max }^{\prime}}^{X 2 \max }}$ & $b_{0}=y_{\text {min }}^{\prime 11_{2 m i n}}$ \\
\hline 11.2 & 27 & $\begin{array}{c}0.142 \\
y_{2}^{\prime}=0,142 \cdot X_{2}-1,585346\end{array}$ & -1.585 \\
\hline$X_{3 \min }$ & $X_{3 \max }$ & $b_{1}=\frac{y}{\min _{\prime_{\max }^{X 3 \max }}^{X \min }}$ & $b_{0}=y_{\text {min }}^{\prime 1_{3 \min }}$ \\
\hline 0.39 & 0.6 & $\begin{array}{c}1.0688 \\
y_{3}^{\prime}=1.06885 \cdot X_{3}-4.16278\end{array}$ & -4.1627 \\
\hline
\end{tabular}

\section{CONCLUSIONS}

Based on models of production functions, a method for evaluating the effectiveness of a compatible interaction of functional subsystems, each of which can have an independent character of application of its results at the stages of design, manufacturing and operation was proposed. It allows us to formulate the conditions for effective management and self-organization of processes for ensuring the quality of complex products as an open dynamic information system and apply the synergetic approach and the ideas of thermodynamics of irreversible processes to production processes and quality assurance models.

The organizational structure of the processes of designing, manufacturing and exploitation of machine-building products of industrial and technical purpose based on the use of multifunctional and multi-element complex technical systems is theoretically substantiated. CTS interact to provide a qualitatively new set of properties and the extent of utility products through information, material and energy resources, which is the object of appropriate changes at each hierarchical level rd. As the basic chosen principles of polymorphism and multicriteria, which were used in the complex description and study of the tasks of analysis and synthesis of structural dynamics of complex technical systems.

When forming the function of production, it is proposed to use a generalized desirability function. An important advantage of this technique is the possibility of transition to dimensionless indicators, which are obtained based on available statistical, expert and other types of data on the processes of design, manufacture and operation of machine-building products in the past and in the future. An effective solution is regulated by the necessary level of desirability, adopted for each particular process, which is modelled based on providing the optimal conditions for its functioning and necessary characteristics of the product.
The proposed methodology can be used in order to ensure that all the necessary requirements are taken into account at the beginning of product design, reduce resource costs and improve the quality of the processes. Moreover, the proposed step-by-step algorithm can be applied to determine optimized values of production functions, which is an integrated result of the operation of all elements in the design and operation processes aimed to provide the appropriate choice of both external engineering system and software for their updated setup and operation under various conditions.

\section{ACKNOWLEGEMENT}

The authors would like to thank the KEGA grant agency for supporting research work within the project KEGA O04TUKE-4/2017.

\section{REFERENCES}

[1] M. Balara, D. Duplakova and D. Matiskova. "Application of a signal averaging device in robotics 2018". Measurement, vol. 115, pp. 125-132, 2018.

[2] P. Cacko and T. Krenicky. "Impact of lubrication interval to operating status of bearing". Applied Mechanics and Materials, vol. 616, pp. 151-158, 2014. ISSN 1660-9336.

[3] H. Dong Wang, G. Le Chang, J. Ping Deng, J. Jie Zheng and Y. Lin Zhao. "Theoretical Research on New Method of Highway Engineering Quality Supervision and Management-Comprehensive Six Sigma Quality Management". Applied Mechanics and Materials, vols. 584-586, pp. 2250-2263, 2014.

[4] M. Durdan, B. Stehlikova, M. Pastor, J. Kacur, M. Laciak and $\mathrm{P}$. Flegner. "Research of annealing process in laboratory conditions". Measurement, vol. 73, pp. 607-618, 2015. ISSN 0263-2241.

[5] T. Hang Wang and P. Jun Zheng. "Analysis of Usability of ECDIS Human-Machine Interface", Applied Mechanics and Materials, vols. 519-520, pp. 1397-1400, 2014.

[6] ISO 9001:2015. Quality management systems - Requirements [Electronic resource]. - Mode of access: https://www.iso.org

[7] ISO 14001:2015. Environmental management systems Requirements with guidance for use [Electronic resource]. - Mode of access: https://www.iso.org

[8] ISO 45001:2018. Occupational health and safety management systems - equirements with guidance for use [Electronic resource]. - Mode of access: https://www.iso.org

[9] ISO/TS 22163:2017. Railway applications - Quality management system - Business management system requirements for rail organizations: ISO 9001:2015 and particular requirements for application in the rail sector [Electronic resource]. - Mode of access: https://www.iso.org

[10] J. Jurko, M. Džupon, A. Panda and J. Zajac. "Study Influence of Plastic Deformation a New Extra Low Carbon Stainless Steels XCr17Ni7MoTiN under the Surface Finish when Drilling". Advanced Materials Research, vols. 538541, pp. 1312-1315, 2012.

[11] T. Krenicky. "Monitoring of Technical Systems Operation Using Virtual Instrumentation". Strojarstvo extra, no. 5, pp. 25/1-25/2, 2010. ISSN 1335-2938.

[12] C. Militaru, C. Juganaru, A.A. Abdel Rahim and A.M. Avramescu. "Some Considerations Regarding the Management Review in Certification Audit Process of Environmental Management System". Applied Mechanics and Materials, vol. 760, pp. 733-738, 2015. 
[13] K. Monkova and P. Monka. "Some aspects influencing production of porous structures with complex shapes of cells". Lecture Notes in Mechanical Engineering, pp. 267276, 2017.

[14] S. Olejarova, J. Dobransky, J. Svetlik and M. Pituk. "Measurements and evaluation of measurements of vibrations in steel milling process". Measurement, vol. 106, pp. 1825, 2017. ISSN 0263-2241.

[15] A. Panda, J. Duplak and J. Jurko. "Analytical expression of T-vc dependence in standard ISO 3685 for cutting ceramic". Key Engineering Materials, vols. 480-481, pp. 317322, 2011.

[16] A. Panda, J. Duplak, J. Jurko and M. Behun. "New Experimental Expression of Durability Dependence for Ceramic Cutting Tool". Applied Mechanics and Materials, vols. 275-277, pp. 2230-2236, 2013.

[17] M. Prislupcak, A. Panda, M. Jancik, I. Pandova, P. Orendac and Tibor Krenicky. "Diagnostic and Experimental Valuation on Progressive Machining Unit". Applied Mechanics and Materials, vol. 616, pp. 191-199, 2014.
[18] M. Rimar, M. Fedak, A. Kulikov and P. Smeringai. "Study of gaseous flows in closed area with forced ventilation." MM Science Journal, vol. 2018, no. March, pp. 2188-2191, 2018.

[19] J. Su and X. Jing Li. "Production Plan of Information Management System for Virtual Industry". Advanced Materials Research, vols. 765-767, pp. 1271-1274, 2013.

[20] A. Todic, B. Nedeljkovic, D. Cikara and I. Ristovic. "Particulate basalt-polymer composites characteristics investigation". Mater. Des., vol. 32, no. 3, pp. 1677-1683, 2011.

[21] J. Valicek, M. Harnicarova, A. Panda, I. Hlavaty, M. Kusnerova, H. Tozan, M. Yagimli and V. Vaclavik. "Mechanism of Creating the Topography of an Abrasive Water Jet Cut Surface". Machining, joining and modifications of advanced materials, vol. 61, pp. 111-120, 2016.

\section{Viliam Zaloga}

ORCI ID: 0000-0001-7444-485X

Sumy State University, Faculty of Technical Systems and Energy Efficient Technologies

2, Rymskogo-Korsakova st., 40007 Sumy, Ukraine

\section{Konstiantyn Dyadyura}

ORCID ID: 0000-0003-0330-5283

Sumy State University, Faculty of Technical Systems and Energy Efficient Technologies 2, Rymskogo-Korsakova st., 40007 Sumy, Ukraine

e-mail: dyadyura@pmtkm.sumdu.edu.ua

\section{Iryna Rybalka}

ORCID ID: 0000-0001-6648-7219

Sumy State University, Faculty of Technical Systems and Energy Efficient Technologies 2, Rymskogo-Korsakova st., 40007 Sumy, Ukraine

\section{Iveta Pandova}

ORCID ID: 0000-0003-1407-779X

Technical University of Kosice

Faculty of Manufacturing Technologies with a seat in Presov

Sturova 31, 08001 Presov, Slovak Republic

e-mail: iveta.pandova@tuke.sk 